\title{
Nanocomposite Fe-Al Intermetallic Coating Obtained by Gas Detonation Spraying of Milled Self-Decomposing Powder
}

\author{
Cezary Senderowski
}

(Submitted November 6, 2013; in revised form January 29, 2014)

\begin{abstract}
The nanocomposite structure of Fe-Al intermetallic coating, created in situ during gas detonation spraying (GDS) of as-milled self-decomposing powder and containing disordered $8 \mathrm{~nm}$ FeAl nanocrystals, was analyzed using scanning electron microscopy (SEM) with energy-dispersive x-ray (EDX) spectroscopy, transmission electron microscopy (TEM), selected-area electron diffraction (SAED), and $\mathrm{x}$-ray diffraction methods. It is found that the Fe-Al coating is characterized by a sublayer morphology consisting of flattened and partially melted splats containing a wide Al range from about 26 to 52 at. $\%$, as well as $\mathrm{Al}_{2} \mathrm{O}_{3}$ oxides, created in situ at the internal interfaces of splats during the GDS process. The complex oxide films, identified as amorphous $\mathrm{Al}_{2} \mathrm{O}_{3}$, which are formed in the nanocrystalline $\mathrm{Fe}-\mathrm{Al}$ matrix of the GDS coating behave like a composite reinforcement in the intermetallic Fe-Al coating. The combined presence of nanosized subgrains in the $\mathrm{Fe}-\mathrm{Al}$ matrix and the $\mathrm{Al}_{2} \mathrm{O}_{3}$ nanoceramic dispersoids significantly increases the microhardness of the coating.
\end{abstract}

Keywords Gas detonation spraying, multiphase nanocomposite coating (based on $\mathrm{FeAl}$ ), nanocrystalline self-decomposing powder

\section{Introduction}

Iron aluminide-based intermetallic alloys are attractive materials for industrial applications at medium to high temperatures due to their unique properties, which are generally ascribed to their long-range ordered (LRO) crystal structures (Ref 1-4). Consequently, they exhibit relatively good mechanical properties, relatively low density $\left(5.56 \mathrm{~g} / \mathrm{cm}^{3}\right.$ for the $\mathrm{FeAl}$ phase), excellent corrosion resistance (as a result of their ability to create a highly protective $\mathrm{Al}_{2} \mathrm{O}_{3}$ layer), and low cost. It is found that the $\mathrm{B} 2$ ordered $\mathrm{FeAl}$ phase exists in the range from approximately 26 to 52 at.\% $\mathrm{Al}$ depending on the temperature (Ref 4). Near the stoichiometric composition, after prolonged annealing at temperatures ranging from 700 to $1000{ }^{\circ} \mathrm{C}$ with sufficiently slow cooling, the process of longrange ordering of atoms in the solid solution takes place and the superlattice of $\mathrm{FeAl}$ (B2) is maintained up to $1310{ }^{\circ} \mathrm{C}$ (Ref 4$)$.

This long-range ordering strengthens interatomic interactions and makes diffusion more difficult. Near-

Dedicated to the memory of Professor George Bystrzycki, a half year after his death.

Cezary Senderowski, Department of Advanced Materials and Technologies, Military University of Technology, Kaliskiego 2, 00-908 Warsaw, Poland. Contact e-mail: csenderowski@wat.edu.pl. stoichiometric $\mathrm{FeAl}$ (B2) alloys are particularly resistant to recrystallization, creep, and high-temperature corrosion (Ref 2).

Moreover, the ability to form $\mathrm{Al}_{2} \mathrm{O}_{3}$ oxide phases at grain boundaries and also dispersoids within the grains limits dislocation slip and provides increased resistance to creep while significantly reducing the rate of diffusion of undesirable hydrogen and oxygen atoms, which are another crucial cause of the brittleness of $\mathrm{FeAl}$ (B2) alloys (Ref 5-7). In addition, an important feature of $\mathrm{FeAl}$ (B2) alloys is their ability to form stable aluminum oxide $\left(\alpha-\mathrm{Al}_{2} \mathrm{O}_{3}\right)$ on their surfaces, which provides resistance to oxidation and sulfurization at high temperatures, as well as in corrosive sulfide or chloride environments (Ref 5-7). In practical terms, a whole range of gas detonation spraying (GDS) and high-velocity oxy-fuel (HVOF) methods as well as plasma and cold-spraying techniques can be used for production of Fe-Al type alloys in the form of protective coatings, containing a significant fraction of oxide films with the above-mentioned beneficial properties (Ref 8-20). In particular, GDS technology offers practically unlimited possibilities for achieving various chemical compositions through proper control of the spraying parameters (Ref 21-28). Special features that characterize GDS technology are very high kinetic and thermal energies accumulated in the two-phase (gas and powder) metallization stream, which is responsible for the heating and large volume deformation of the powder particles impacting against the metallic substrate and layers of successively deposited coating material.

The fundamental problem with the GDS process is the determination of spraying parameters that ensure that the particles of the powder feedstock remain in the solid state while reaching a temperature at which they undergo 
softening. During the passage of the detonation wave front within the time of $10^{-7}-10^{-5} \mathrm{~s}$ and during the expansion of the gaseous detonation combustion products, partial melting and oxidation of the particle surface may occur (Ref 28, 29). This promotes the formation of a heterogeneous, multiphase structure which resembles an in situ composite having a complex phase structure containing a certain volume fraction of naturally formed $\mathrm{Al}_{2} \mathrm{O}_{3}$ oxide films (formed in situ in the GDS conditions) and micropores (Ref 18-20).

Oxides are formed during the GDS process, in the stage when the detonation wave propagates through the powder particles, which involves rapid chemical reactions accompanied by the release of a large amount of thermal energy (Ref 18-23, 30-32). However, despite the high velocity of the detonation wave, the powder particles can partially melt at their surfaces and then quickly oxidize due to the high concentration of free radicals, eventually solidifying on their approach to the substrate (Ref 28, 29, 32).

Generally, the controlled technological conditions of the GDS process ensure the formation of a coating structure with negligible oxidation of grains and porosity of less than $0.5 \%$, which translates into very high adhesive strength with the metal substrate (retained to a very high temperature range of up to $\left.750^{\circ} \mathrm{C}\right)(\operatorname{Ref} 18,32,33)$. However, the high aluminum content in Fe-Al type powders deposited on structural steel is prone to oxidation during the GDS process, which may change the composition and microstructure of the coatings, resulting in the formation of oxide ceramics (Ref 18, 22). Coatings made from self-decomposing powders with $\mathrm{Fe}-\mathrm{Al}$ phases and aluminum ferrite are particularly valuable due to their good durability, high corrosion resistance (especially at high temperatures), isotropic heat expansibility, and high hardness (Ref 34-36). Considering the economic cost of powder technology, it should be mentioned that the price of self-decomposing powders is about three times lower than the price of powders with the equivalent composition produced by the vacuum inert gas atomization (VIGA) method.

As shown by our previous research results (Ref 18, 19, 21), GDS technology has advantageous effects for spraying of $\mathrm{Fe}-\mathrm{Al}$ intermetallic coatings from self-decomposing Fe-Al powders directly after their manufacture. These coatings are characterized by high durability, low porosity, high corrosion resistance (especially at high temperatures), good hardness, and high adhesive strength to the substrate.

The present work reports the results of studies on the ability of self-decomposing $\mathrm{Fe}-36$ at.\% $\mathrm{Al}$ powder, processed by low-energy milling for $20 \mathrm{~h}$, to form nanocomposite (multiphase) intermetallic $\mathrm{Fe} \mathrm{Al}$ type coatings when processed by the GDS method. The microstructure and chemical homogeneity as well as microhardness of both the feedstock powder material milled for $20 \mathrm{~h}$ and the $\mathrm{Fe}-\mathrm{Al}$ coating directly after the GDS process were investigated using SEM with EDX, TEM, SAED, and $\mathrm{x}$-ray diffraction methods. Based on previous GDS experiments, one expects that gas detonation-sprayed $\mathrm{Fe}-\mathrm{Al}$ type coatings obtained using as-milled self-decomposing powders will inherit the nanocrystalline structure based on the $\mathrm{FeAl}$ phase strengthened by $\mathrm{Al}_{2} \mathrm{O}_{3}$ oxide ceramics, created in situ at the internal interfaces of splats during the GDS process.

\section{Experimental}

Self-decomposing $\mathrm{Fe}-36$ at.\% $\mathrm{Al}$ powder, premilled for $20 \mathrm{~h}$ at $150 \mathrm{rpm}$ in impact mode in a Uni Ball-Mill 5 magneto ball mill, was used as the starting material for GDS. The milled powder was screened in a Fritsch Analysette Pro 3 vibrational shaker to extract the 38-75$\mu \mathrm{m}$ fraction, which is the most suitable fraction for the GDS process. Assessment of chemical uniformity, morphology, and grain size was conducted using a scanning electron microscope equipped with an X-ray microanalysis system (Philips XL30/LaB6-DX4i-EDAX). In addition, the morphology and chemical composition of the coating layers or grains and the substructure of individual splats were analyzed using a Philips CM 20 TWIN transmission electron microscope operating at $200 \mathrm{kV}$. Thin foils for TEM observations were prepared by cross-sectioning the coating perpendicular to the coating-substrate interface by thinning with a gallium focused ion beam (FIB, Quanta 3D). Selected area electron diffraction (SAED) was performed with the TEM to analyze the type and degree of ordering of the investigated phases. Automatic $\mathrm{x}$-ray spectrum phase analysis was also done using a Seifert 3003 diffractometer with an x-ray phase analyzer using Co $\mathrm{K}_{\alpha}$ radiation $(\lambda=0.178897 \mathrm{~nm})$. An angular step size of $0.02 \% \mathrm{~min}$ and step time of $5 \mathrm{~s}$ per point were used. The distribution of coating hardness in the layered structure and commercially manufactured powder after milling as well as reference powder was evaluated by the Vickers method using a Shimadzu microhardness tester (100 g load for $5 \mathrm{~s}$ ).

The reference powder was heated for $100 \mathrm{~h}$ at $1000{ }^{\circ} \mathrm{C}$ to assess the degree of ordering of the $\mathrm{FeAl}$ phase, as the main structural component of the coating material.

The long-range order (LRO) parameter for the FeAl phase is defined as

$$
\mathrm{LRO}=\sqrt{\frac{\left(I_{\mathrm{s}} / I_{\mathrm{F}}\right)_{\mathrm{dis}}}{\left(I_{\mathrm{s}} / I_{\mathrm{F}}\right)_{\mathrm{hr}}},}
$$

where $\left(I_{\mathrm{S}} / I_{\mathrm{F}}\right)_{\text {dis }}$ and $\left(I_{\mathrm{S}} / I_{\mathrm{F}}\right)_{\text {ord }}$ are the ratios of the integrated intensities (peak area) of the superlattice reflection to the fundamental line for the disordered ("dis," i.e., as-milled) and reference ("ord") powders, respectively.

For the LRO parameter calculations, the intensity of the $(100)_{\mathrm{S}}$ and $(200)_{\mathrm{F}}$ diffraction peaks was selected to represent the superlattice and fundamental peak, respectively.

The GDS process was carried out on AISI 1045 plain carbon steel at the optimum parameter values (discussed in Ref 18), which guarantees repeatability of the metallic spray properties in each working cycle. 


\section{Results and Discussion}

The Fe-Al self-decomposing powders were produced in the Department of Materials Science of the Silesian Technical University. Their complex chemical composition and properties were considered to assess the possibility of their application in the GDS process. As shown in Fig. 1, it was established that the self-decomposing $\mathrm{FeAl}$ type intermetallic powders after $20 \mathrm{~h}$ of milling, despite having a very similar range of particle sizes, showed varying morphology of grains as well as a wide range of chemical compositions in the individual powder particles. As shown in Fig. 1b, EDX point microanalysis of the $20 \mathrm{~h}$ milled self-decomposing powders revealed considerably varying chemical composition with various aluminum contents in the individual particles, and a significant content of oxygen (Table 1). This suggests that the selfdecomposing powder is a secondary solid solution based on $\mathrm{Fe}-\mathrm{Al}$ phases with a wide range of oxidized aluminum content.

Based on measurements of 10 randomly selected powder particles, the nominal concentration of $\mathrm{Al}$ was found to be $28-48$ at.\%. The degree of chemical heterogeneity of the powder particles is represented by the varying degree of grayness in the individual particles in the backscattered electron (BSE) image in Fig. 1b. This shows that there is some extent of phase inhomogeneity arising from the wide range of content of alloying elements in the Fe-Al intermetallic phase solutions. However, the observed inhomogeneity is to some extent also a consequence of the presence of oxygen in the form of oxide films on the surface of grains, as shown in Table 1 .

The results of both chemical point microanalysis (Fig. 1b; Table 1) and the mapping of the $\mathrm{Fe}, \mathrm{Al}$, and $\mathrm{O}$ elements (Fig. 2) form the basis for identification of oxide films on the surface of the as-milled Fe-Al self-decomposing powder particles. The results prove that oxygen, apart from clearly defined $\mathrm{Al}_{2} \mathrm{O}_{3}$ aluminum oxides, is mainly present in the areas of grains with high aluminum content (imaged as dark grey and grey) as well as in the light areas identified as $\mathrm{Fe}_{3} \mathrm{Al}$. The high oxygen content favoring $\mathrm{Al}_{2} \mathrm{O}_{3}$ oxide formation is certainly the result of the melting and casting conditions as well as the solidification of the cast ingots in the casting mold. Additionally, the kinetics of the self-decomposition process, as well as during the $20 \mathrm{~h}$ of milling, of the powder are important.

According to the literature (Ref 35,36 ), the ingot's matrix plays the major role in the self-decomposition process. Based on the aluminum content, the matrix can acquire various phases such as the $\mathrm{FeAl}$ phase mixed with aluminum ferrite (29-34 at.\% $\mathrm{Al}), \mathrm{FeAl}(24-36$ at.\% $\mathrm{Al}$ ), $\mathrm{FeAl}$ and $\mathrm{FeAl}_{2}$ (36-45 at.\% $\mathrm{Al}$ ), $\mathrm{FeAl}_{2}$ and $\mathrm{Fe}_{2} \mathrm{Al}_{5}$ (over 45 at. $\% \mathrm{Al}$ ), as well as $\mathrm{Al}_{2} \mathrm{O}_{3}$ oxide ceramics. The aluminum ferrite and $\mathrm{FeAl}$ phases have relatively high tensile strength (over $250 \mathrm{MPa}$ ), but the $\mathrm{FeAl}_{2}$ and $\mathrm{Fe}_{2} \mathrm{Al}_{5}$ highaluminum phases are very brittle with tensile strength not exceeding $15 \mathrm{MPa}$ (Ref 35). The presence of $\mathrm{FeAl}_{2}$ traces significantly decreases the critical stress level in the cast ingot, accelerating initial crack formation.

In addition, the presence of $\mathrm{Al}_{2} \mathrm{O}_{3}$ oxide impacts on the final properties of the self-decomposing powder, creating a composite structure of the powder material. The verification of the phase structure of the self-decomposing powder in the initial state (as-received from the manufacturer) and also after $20 \mathrm{~h}$ of milling (Fig. 3) shows that reflections, typical for $\mathrm{FeAl}$ intermetallic phase, can be identified with specific $\{100\}$ reflection originating from a superlattice with B2 order. The increase of the half-width of the FeAl reflections (Fig. 3) for the powder particles after low-energy milling indicates an increase of residual
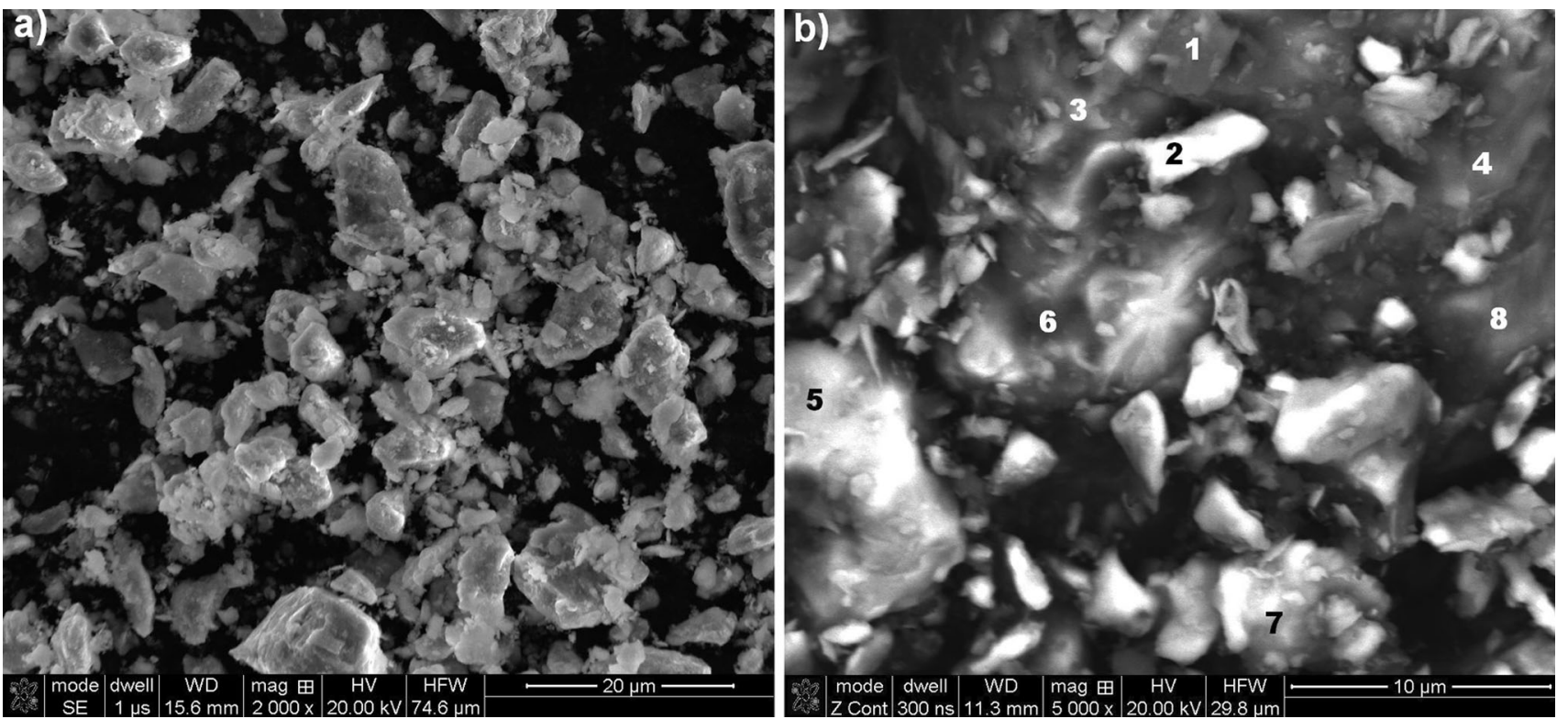

Fig. 1 (a) Morphology of Fe-Al self-decomposing powder particles after $20 \mathrm{~h}$ of milling. (b) Point microanalysis of the chemical composition in individual particles 
Table 1 Chemical composition characteristics of as-milled self-decomposing powder particles as determined by EDX point microanalysis

\begin{tabular}{|c|c|c|c|c|}
\hline \multirow[b]{2}{*}{ Designation of particle area according to Fig. $1 \mathrm{~b}$} & \multirow[b]{2}{*}{ Remarks } & \multicolumn{3}{|c|}{ Content, at. $\%$} \\
\hline & & $\mathbf{F e}$ & Al & $\mathbf{O}$ \\
\hline \multicolumn{5}{|c|}{ As-milled powder particles (after $20 \mathrm{~h}$ of milling), Fig. $1 \mathrm{~b}$} \\
\hline 1 - Dark grey & Aluminum oxide films & 8.9 & 43.5 & 47.6 \\
\hline 6 - Dark grey & & 7.3 & 44.1 & 48.7 \\
\hline 4 - Grey & FeAl strongly oxidized & 22.2 & 48.4 & 29.4 \\
\hline 8 - Grey & & 33.0 & 43.0 & 24.0 \\
\hline 3 - Light grey & FeAl oxidized & 39.8 & 42.0 & 18.2 \\
\hline 7 - Light grey & & 41.9 & 38.9 & 19.2 \\
\hline 5 - Dark white & FeAl lightly oxidized & 57.1 & 35.4 & 7.5 \\
\hline 2 - White & $\mathrm{Fe}_{3} \mathrm{Al}$ lightly oxidized & 66.4 & 28.2 & 5.4 \\
\hline
\end{tabular}
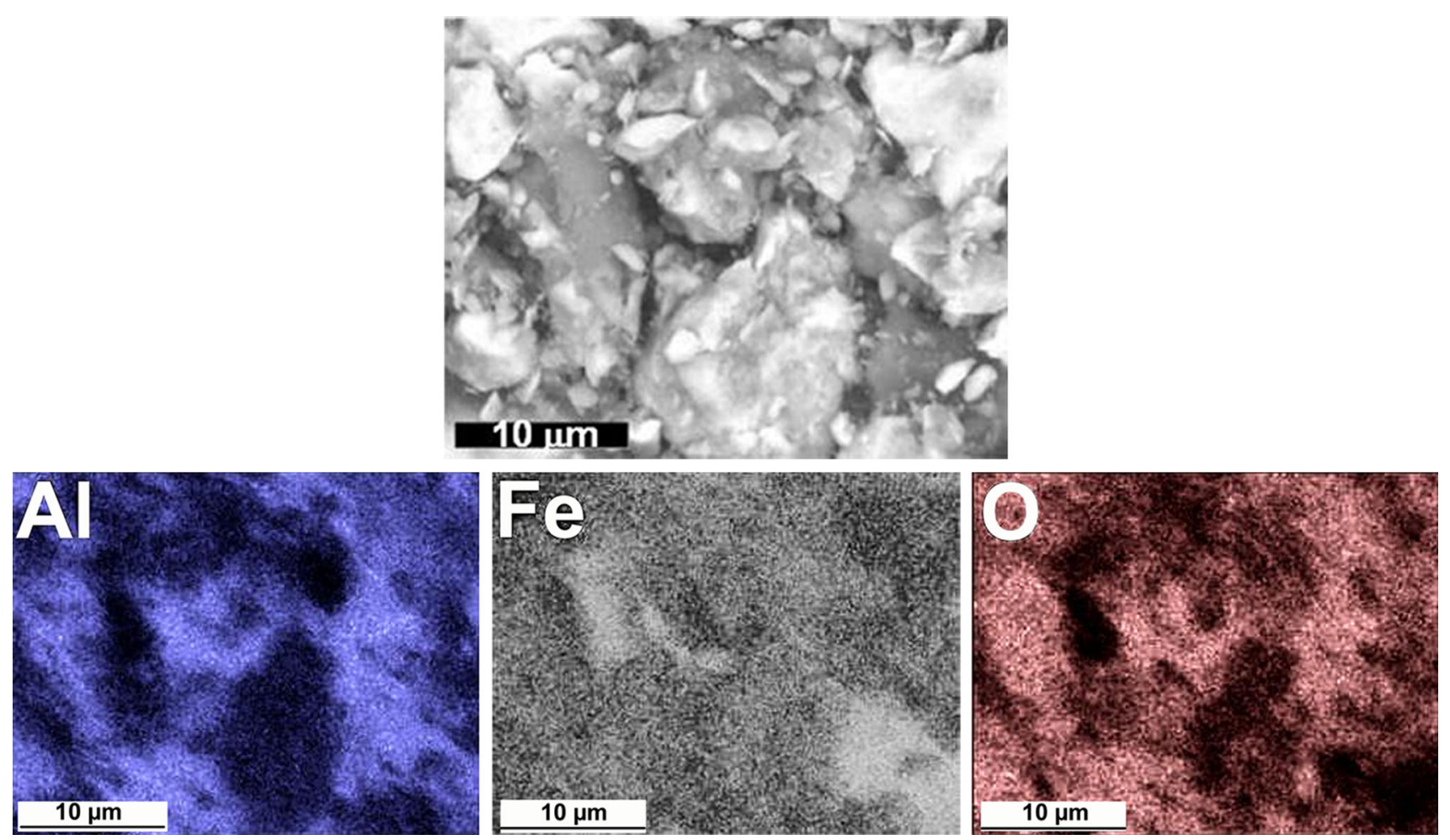

Fig. 2 SEM images of self-decomposing powder particles after $20 \mathrm{~h}$ of milling and corresponding EDX maps of Fe, Al, and O distribution

stresses and fragmentation of the coherently dispersing zones after $20 \mathrm{~h}$ of milling, which translates into measurable lattice strains and a change of the crystallite size (Fig. 4). The slight microhardness increase (Fig. 5) implies that the increase of the component of the reflections assigned to the presence of residual stresses is minor, meaning that the broadening of the reflections is dominated by the crystallite fragmentation phenomenon.

Based on the results obtained (using Scherrer's method), it is found that crystallite fragmentation of the as-milled powder particles (Fig. 4) reaches the level of $8 \mathrm{~nm}$ (after $20 \mathrm{~h}$ of milling), indicating the formation of a nanocrystalline structure of the investigated powder material after milling. Low-energy milling also causes a decrease of the $\mathrm{FeAl}$ secondary solution ordering degree (Fig. 4), but the B2 superlattice is still retained, as evidenced by the (100) peak in the XRD pattern in Fig. 3. Even though the disordering of the secondary solution reduces the particle strengthening, this is compensated by strengthening originating from the crystallite fragmentation, so the microhardness increase is negligible with milling time extension (Fig. 5). An increase of the microhardness may also be related to the density increase of antisite-atom pairs $\left(\mathrm{Fe}_{\mathrm{Al}}, \mathrm{Al}_{\mathrm{Fe}}\right)$ as evidenced by the growth of the lattice parameter $a$ of the $\mathrm{FeAl}$ phase shown in Fig. 3.

As reported by Varin et al. (Ref 37), an even greater increase in microhardness (up to about $400 \mathrm{HV} 0,1$ ) with 


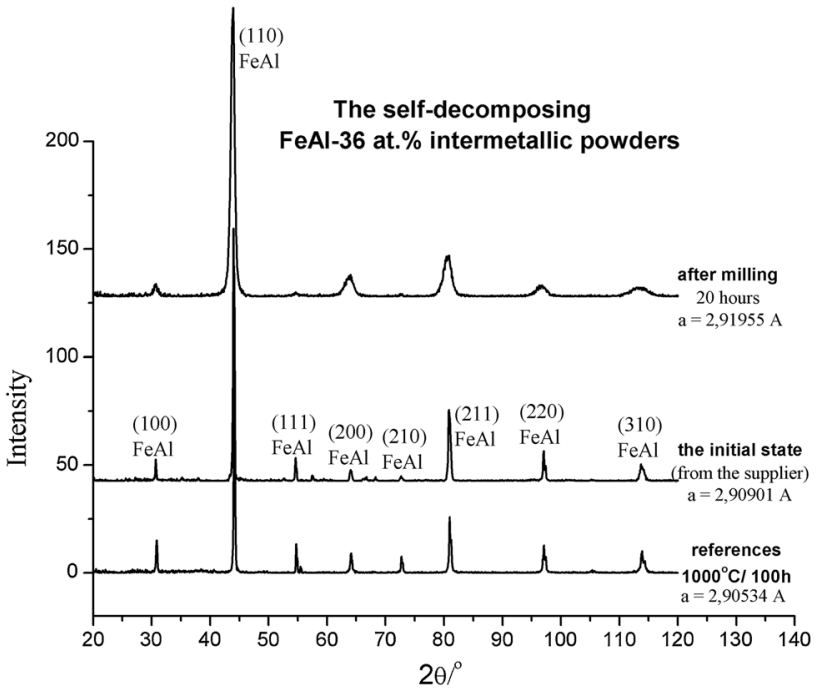

Fig. 3 XRD patterns of self-decomposing $\mathrm{Fe}-36$ at. $\% \mathrm{Al}$ powder in the initial state (from the manufacturer) as well as after $20 \mathrm{~h}$ of milling, and of the reference powder (heated for $100 \mathrm{~h}$ at $1000{ }^{\circ} \mathrm{C}$ and quenched at $2{ }^{\circ} \mathrm{C} / \mathrm{min}$ to room temperature in argon)

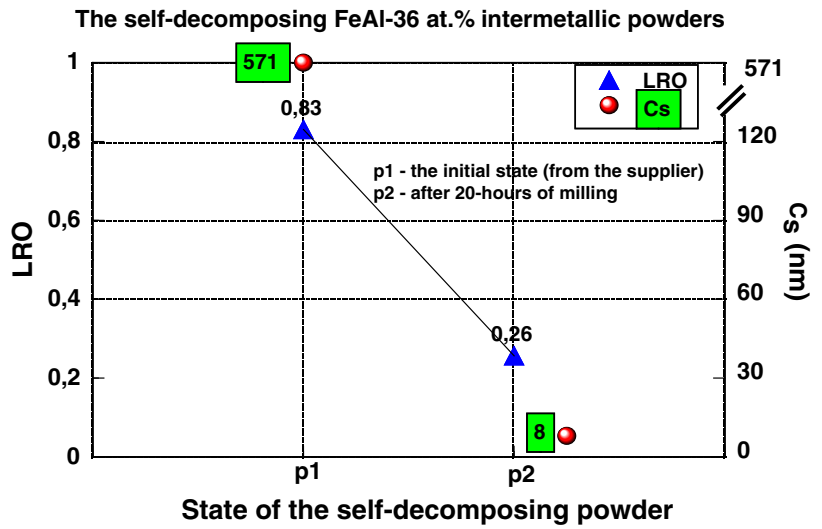

Fig. 4 Long-range ordering (LRO) and crystallite size $\left(C_{\mathrm{s}}\right)$ of self-decomposing $\mathrm{Fe}-36$ at. $\% \mathrm{Al}$ powder in a particular state (according to legend)

complete disorder of the B2 superlattice and a nanocrystallite size of about $7 \mathrm{~nm}$ was obtained for as-milled $\mathrm{Fe}-45$ at. $\% \mathrm{Al}$ powder after $47 \mathrm{~h}$ of milling. The complete destruction of the LRO in the $\mathrm{B} 2 \mathrm{FeAl}$ with milling time up to $47 \mathrm{~h}$ and the creation of a disordered A2 ferromagnetic structure are related to antiphase domain reduction due to the gradual disappearance of long-range ordering. It must also be noted that, according to Varin et al. (Ref 37), such high microhardness of the as-milled powder can be attributed to the solid-solution hardening mechanism.

The present analysis of Fe-36 at.\%Al self-decomposing powders after $20 \mathrm{~h}$ of milling shows that the decrease of the LRO parameter should enhance their susceptibility to plastic deformation in the GDS process despite the small increase of the microhardness of the particles due to their

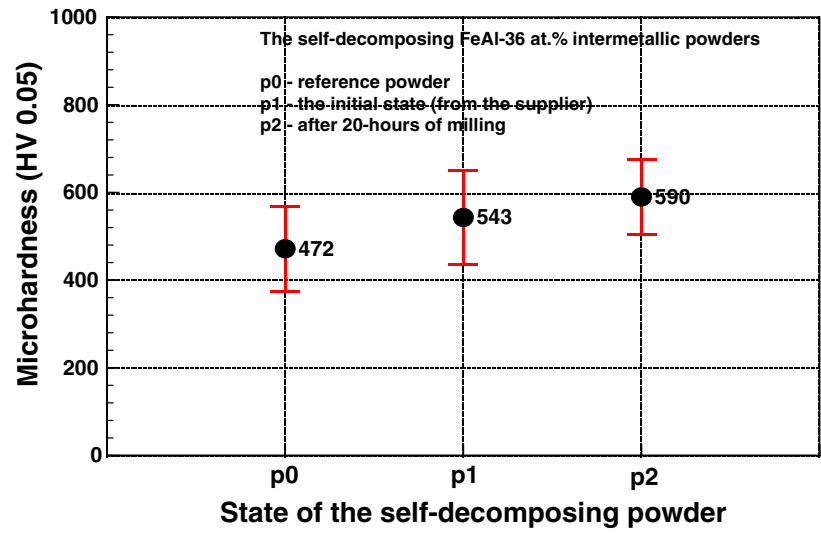

Fig. 5 Average microhardness and standard deviation of selfdecomposing $\mathrm{Fe}-36$ at. $\% \mathrm{Al}$ powder in a particular state (according to legend)

nanocrystalline structure. At the same time, the formation of nanograins in the self-decomposing powder particles allows one to assume that this microstructure will be inherited in the as-sprayed coatings. This should also be a reason for cohesive strength increase despite the presence of $\mathrm{Al}_{2} \mathrm{O}_{3}$ ceramics which render the GDS coatings like a nanocomposite.

After the aforementioned investigation of the physicochemical features of the milled self-decomposing FeAltype powder, it was used in the GDS process. It was found that very intensive plastic deformation of the solid powder particles occurred if they are at a temperature close to their melting point when the spraying parameters used for processing are employed for deposition of as-milled FeAl self-decomposing powders on the substrate. It was observed that the GDS coating was built from "flattened" grains distributed in a layer mode (Fig. 6). They were formed by unmelted or partially melted (especially Al-rich) particles which underwent geometrical changes during the GDS process due to strong plastic deformation. The presence of partially melted particles depends on the heat transfer efficiency resulting mainly from the dynamics of the GDS process as well as the aluminum content and the structural conditions of the Fe-Al self-decomposing particles with inhomogeneous composite-like structure containing oxide phases.

The limitations of the heat transfer efficiency resulting mainly from the dynamics of the GDS process and the structural conditions of the particles of the FeAl powder feedstock with inhomogeneous composite-like structure, containing pores and oxide phases, were presented by Senderowski et al. (Ref 29).

Based on the results of scanning electron microscopy and EDX point microanalysis, it is shown (Fig. 6b) that the layered arrangement of flattened grains based on the $\mathrm{Fe}-\mathrm{Al}$ phases reveals a varied chemical composition with an extended range of secondary solid solution from 26 to 52 at. \% Al (Table 2). This wide range of compositions implies local occurrence of $\mathrm{Fe}_{3} \mathrm{Al}$ phase with decreased $\mathrm{Al}$ content as observed as the brightest areas in the BSE image (Fig. 6b) as well as a dark-grey phase of $\mathrm{FeAl}_{2}$ type 

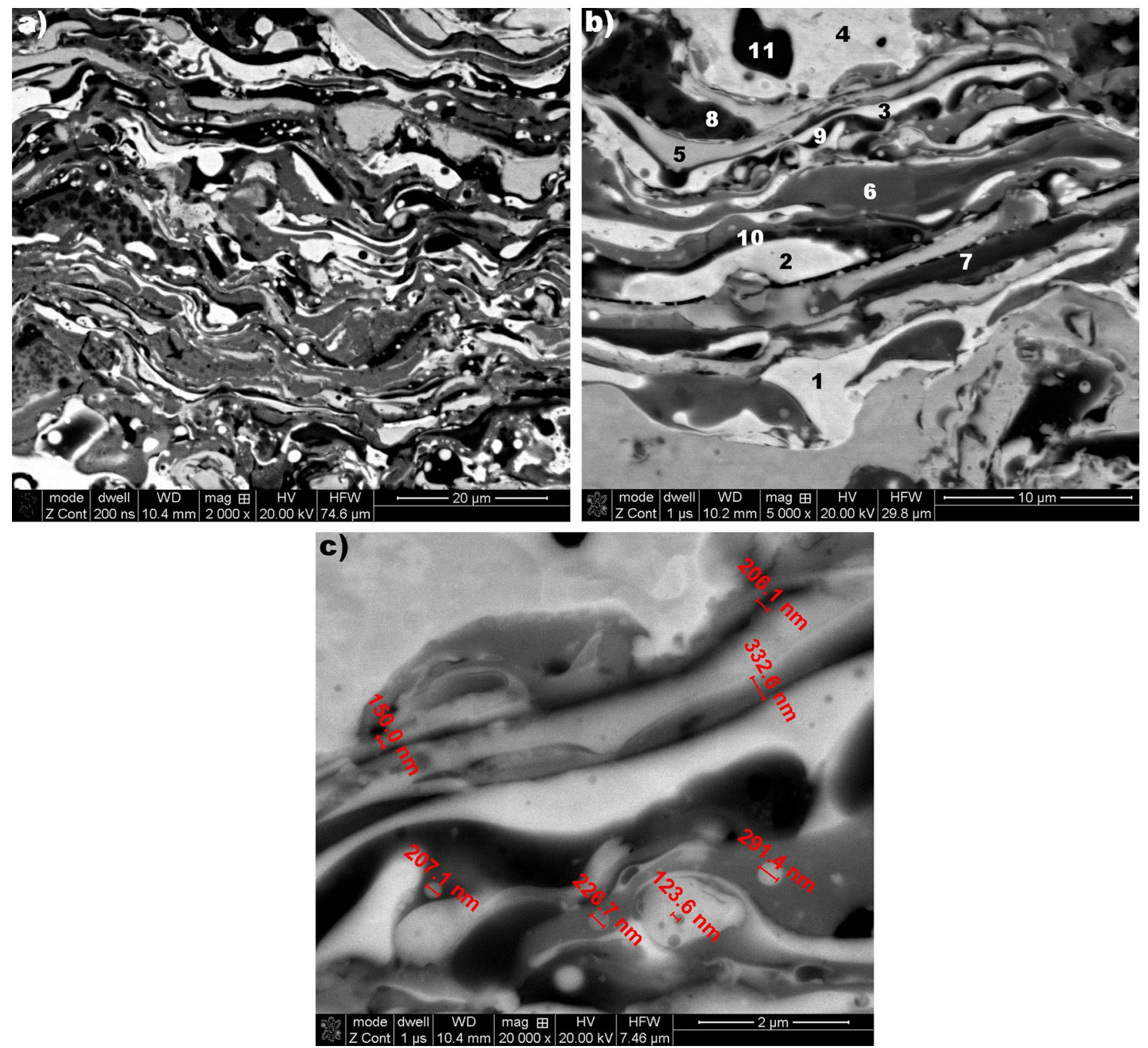

Fig. 6 (a) Typical composite-like microstructure of gas detonation-sprayed Fe-Al intermetallic coating exhibiting phase heterogeneity, as confirmed by (b) EDX point analysis involving nano-aluminum oxides (c)

with $\mathrm{Al}$ content higher than the upper limit for the $\mathrm{FeAl}$ phase (Table 2). The evident composite-like morphology of the FeAl type coating is related to the presence of dispersed intermetallic phases in the various stages of ordering (depending on the $\mathrm{Al}$ content). This effect is also due to the considerable oxygen contribution, which is the reason for the occurrence of the stable layers of oxides such as $\alpha-\mathrm{Al}_{2} \mathrm{O}_{3}$ as well as more complex ones of $\mathrm{Fe}+2$ $\mathrm{Al}_{2} \mathrm{O}_{4}$ type as identified by the $\mathrm{x}$-ray diffraction technique (Fig. 7).

The Al-rich Fe-Al self-decomposing powder was chemically active during GDS spraying (although generally highly resistant to oxidation) as thin oxide films covering significant areas of the free surfaces of the powder particles during spraying were later identified in the interlamellar grain boundaries of the coating (Fig. 6). The formation of oxide films as identified on the basis of XRD patterns (Fig. 7) and point EDX analysis (darkest areas of the coating structure in Fig. 6) leads to the lamellar structure of the $\mathrm{FeAl}$ intermetallic coatings and defines their composite character. Besides the presence of the $\mathrm{FeAl}$ intermetallic phase, which is the basic structural component for the original powder material, the $\mathrm{x}$-ray diffraction results (Fig. 7) also identified complex oxides $\left(\mathrm{Fe}+2 \mathrm{Al}_{2} \mathrm{O}_{4}\right)$ occurring across the entire volume of the coating, which alternatively could be approximately identified as equivalent to $\mathrm{Al}_{2} \mathrm{O}_{3}$.

As shown in Fig. 8, TEM analysis performed on grains located in the central zone at depth of about $200 \mu \mathrm{m}$ from the surface of the as-sprayed coating indicated the 
Table 2 Microanalysis of chemical composition of gas detonation-sprayed Fe-Al type coating deposited with as-milled self-decomposing powder particles

\begin{tabular}{|c|c|c|c|c|c|}
\hline \multirow{2}{*}{$\begin{array}{l}\text { Designation of grain area } \\
\text { according to Fig.6b }\end{array}$} & \multirow[b]{2}{*}{ Remarks } & \multicolumn{3}{|c|}{ Content, at. $\%$} & \multirow{2}{*}{$\begin{array}{l}\text { Participation } \\
\text { in coating, vol. } \%\end{array}$} \\
\hline & & $\mathbf{F e}$ & Al & $\mathbf{O}$ & \\
\hline \multicolumn{6}{|c|}{ As-sprayed nanocomposite-like Fe-Al coating (after GDS process), Fig. 6b } \\
\hline 1. Dark white & $\mathrm{Fe}_{3} \mathrm{Al}$ strongly oxidized & 50.3 & 33.5 & 16.2 & $22.4 \pm 4.5$ \\
\hline 2. Dark white & & 39.5 & 31.6 & 28.9 & \\
\hline 3. Dark white & $\mathrm{Fe}_{3} \mathrm{Al}$ very strongly oxidized & 40.7 & 26.7 & 32.6 & \\
\hline 4. Dark white & & 37.4 & 27.9 & 34.7 & \\
\hline 5. Light grey & FeAl lightly oxidized & 49.2 & 38.2 & 12.6 & $67.5 \pm 4.7$ \\
\hline 6. Grey & FeAl oxidized & 33.6 & 42.2 & 24.2 & \\
\hline 7. Dark grey & FeAl very strongly oxidized & 18.2 & 42.0 & 39.8 & \\
\hline 8. Dark grey & $\mathrm{FeAl}_{2}$ oxidized & 19.2 & 52.1 & 28.7 & $2.7 \pm 1.0$ \\
\hline 9. Dark & $\mathrm{Al}_{2} \mathrm{O}_{3}$ oxide films & 2.1 & 34.7 & 63.2 & $7.4 \pm 2.4$ \\
\hline 10. Dark & & 9.3 & 31.4 & 59.3 & \\
\hline 11. Dark & $\mathrm{Al}_{2} \mathrm{O}_{3}$ oxide particle & 5.1 & 30.2 & 64.7 & \\
\hline Average from all areas & $\begin{array}{l}\text { Multiphase composite-like } \\
\text { structure based on oxidized } \\
\text { Fe-Al phases and aluminum } \\
\text { oxides }\end{array}$ & 33.3 & 37.6 & 29.1 & $\ldots$ \\
\hline Porosity & $\ldots$ & $\ldots$ & $\ldots$ & $\ldots$ & 0.4 \\
\hline
\end{tabular}

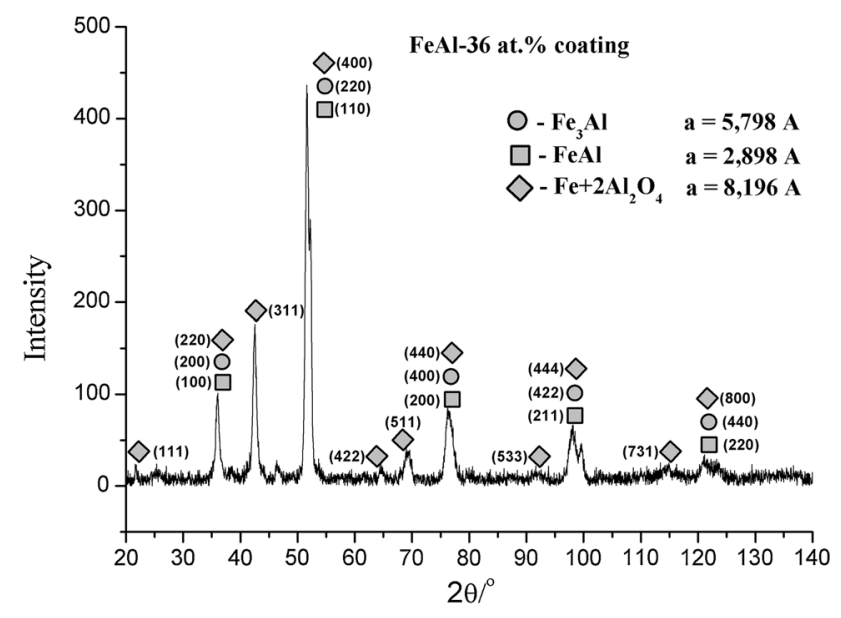

Fig. 7 XRD pattern of as-sprayed coating from milled FeAl self-decomposing powder

presence of a very complex fine-grained structure with nanocrystalline grains with a significant density of dislocations and ordered antiphase domains (APDs). Subgrains show a homogeneous single-phase structure with relatively large areas of $\mathrm{B} 2 \mathrm{FeAl}$ ordered antiphase domains ranging in size from 30 to $80 \mathrm{~nm}$ (Fig. 8b). However, selected TEM dark-field micrographs and diffraction patterns also revealed much smaller areas of $\mathrm{D0}_{3} \mathrm{Fe}_{3} \mathrm{Al}$ ordered antiphase domains with average size of about $20 \mathrm{~nm}$, as shown in Fig. 8c. The presence of the B2 and $\mathrm{D}_{3}$ APD structures is good evidence of fragmentation of very fine grains within a dual-phase $\mathrm{FeAl}$ and $\mathrm{Fe}_{3} \mathrm{Al}$ structure. It also confirms that the nanocrystalline B2 FeAl superlattice was inherited from the as-milled selfdecomposing powder under the experimental conditions of the GDS process.

The preferential location for $\mathrm{Fe}_{3} \mathrm{Al}$ phase formation is the nearest boundary to the oxide phases formed in situ under the GDS conditions, which are characterized by $\mathrm{Al}$ depletion to the range of 26-33 at.\% (Fig. 8c). The nanocrystalline lamellar subgrains were identified as $\mathrm{Fe}_{3} \mathrm{Al}$ phase with a significant density of dislocations, undoubtedly originating from the internal compressive stresses caused by the high impulse pressure and high kinetic energy of the high-velocity powder particles during the GDS process as well as the presence of dispersive thin films of hard $\mathrm{Al}_{2} \mathrm{O}_{3}$ oxides. As a result of the high temperature of the GDS metallization stream as well as the very high kinetic energy of the powder particles during their collision with the substrate, some powder particles are partially melted and aluminum reacts with oxygen to form oxides, mainly in the form of alumina thin films that undergo amorphization (Fig. 8a). Most probably, the amorphous structure of the $\mathrm{Al}_{2} \mathrm{O}_{3}$ oxides and their high dispersion within the structure of the as-sprayed $\mathrm{FeAl}$ coating are both responsible for the absence of $\mathrm{Al}_{2} \mathrm{O}_{3}$ diffraction peaks in the diffraction pattern in Fig. 7.

Both the TEM bright-field micrographs and the SAED pattern (Fig. 8a) confirm the presence of an amorphous phase containing a sequence of sublayers with thickness of up to $500 \mathrm{~nm}$ and length of about $5 \mu \mathrm{m}$. The EDX spectrum corresponding to this amorphous area (Fig. 8d) reveals the $\mathrm{Al}_{2} \mathrm{O}_{3}$ phase. Comparatively, other amorphous sublayers observed by TEM in the as-sprayed Fe-Al type coating revealed oxide layers with thicknesses in the range from 50 to $300 \mathrm{~nm}$. At the same time, it was found that, in the area of polycrystalline dispersive structure created from strongly plasticized $\mathrm{FeAl}$ nanograins, nanocrystalline particles of oxides identified as $\mathrm{Al}_{2} \mathrm{O}_{3}$ phase (dark particles in Fig. 9) are also present.

This indicates that the identified $\mathrm{Al}_{2} \mathrm{O}_{3}$ oxides, present in the coating matrix in an amount of about $7.4 \pm 2.4$ vol. $\%$, behave as a composite reinforcement to the nanocrystalline Fe-Al structure of the intermetallic coating. The oxides additionally enhance the contribution from compressive stresses, the value of which reaches 300$600 \mathrm{MPa}$, as reported by Senderowski et al. (Ref 21). Such 

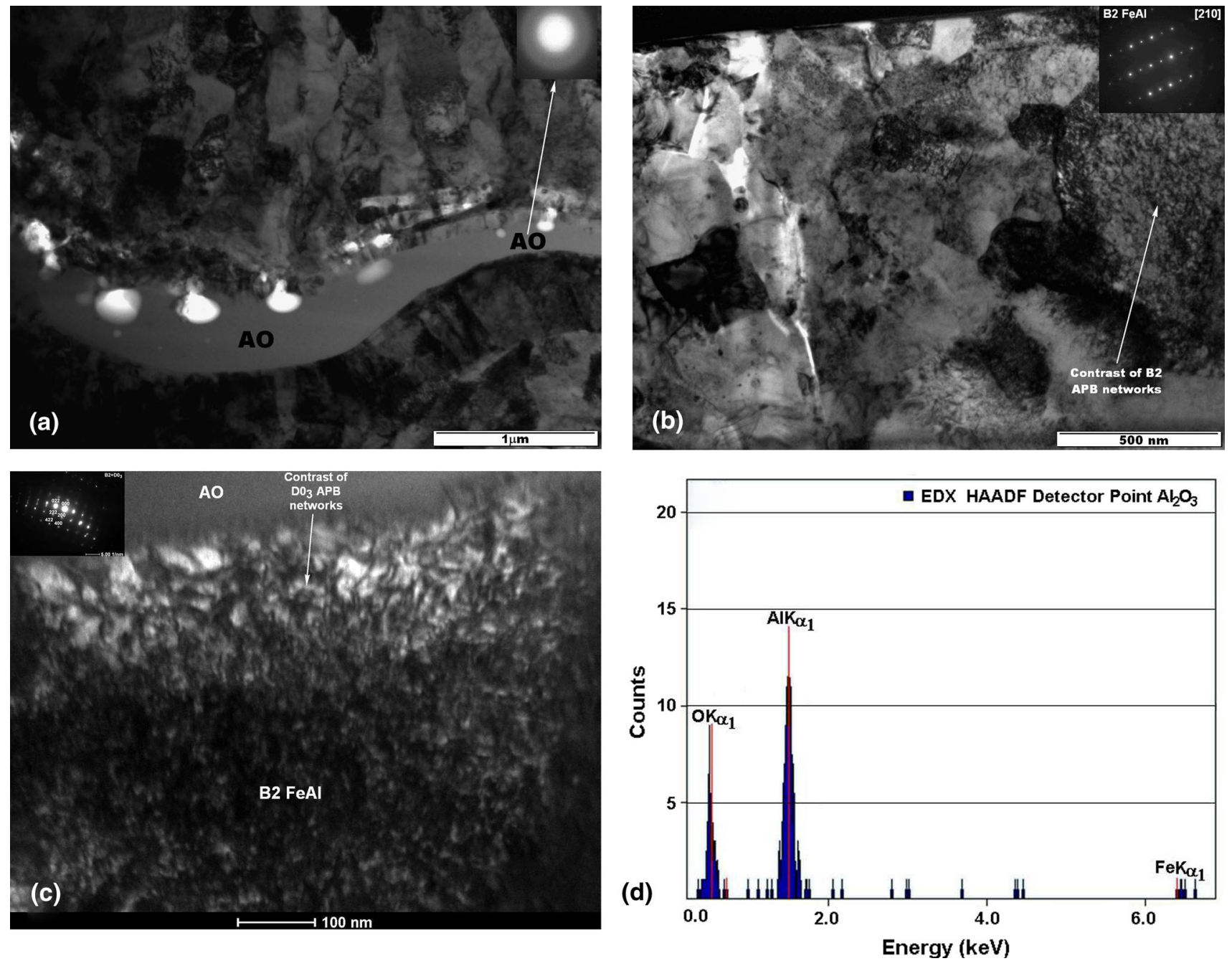

Fig. 8 TEM bright-field micrographs of grains of the as-sprayed coating showing: (a) complex fine-grained structure with amorphous $\mathrm{Al}_{2} \mathrm{O}_{3}$ sublayer as confirmed by the inset diffraction pattern (right corner) and EDX spectrum corresponding to this amorphous area in (d); (b) equiaxed nanocrystalline grains containing typical B2 FeAl networks as confirmed by the inset diffraction pattern (right corner) corresponding to ordered $\mathrm{FeAl}$; (c) another type of ultrafine grain with diphase nanocrystalline $\mathrm{B} 2 \mathrm{FeAl}$ and $\mathrm{DO}_{3} \mathrm{Fe}_{3} \mathrm{Al}$ structure as confirmed by the diffraction pattern (left corner)

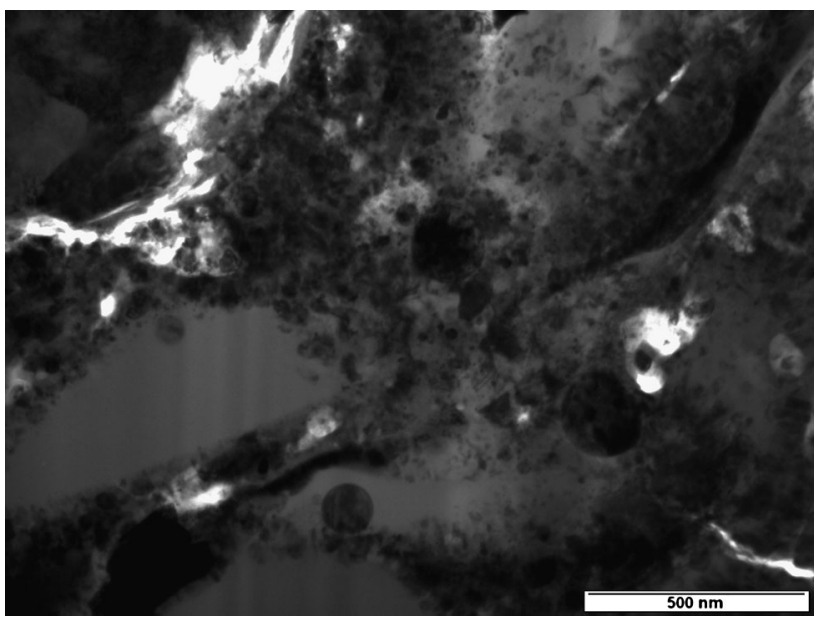

Fig. 9 TEM bright-field micrographs of grains of as-sprayed coating with nanocrystalline particles of aluminum oxides

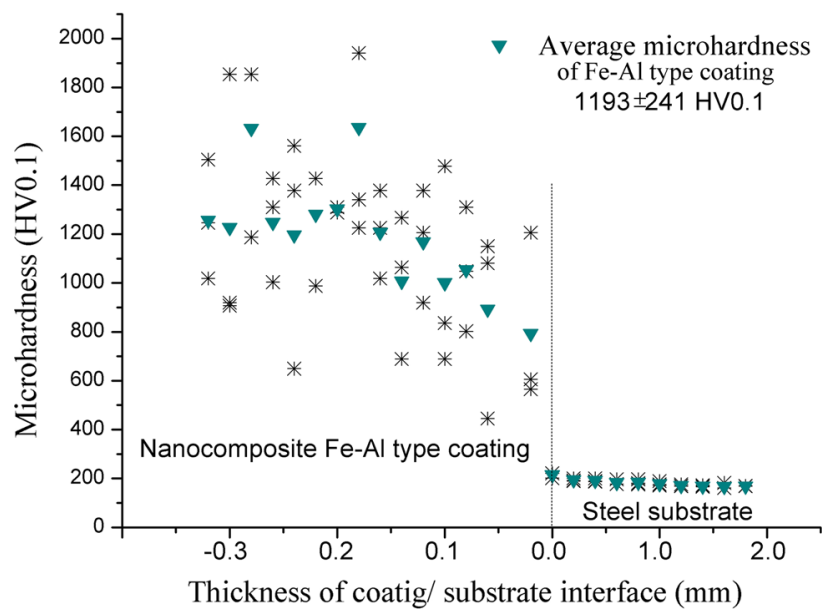

Fig. 10 Microhardness distribution in the distinguished nanocomposite structure of as-sprayed $\mathrm{Fe}-\mathrm{Al}$ intermetallic coating 

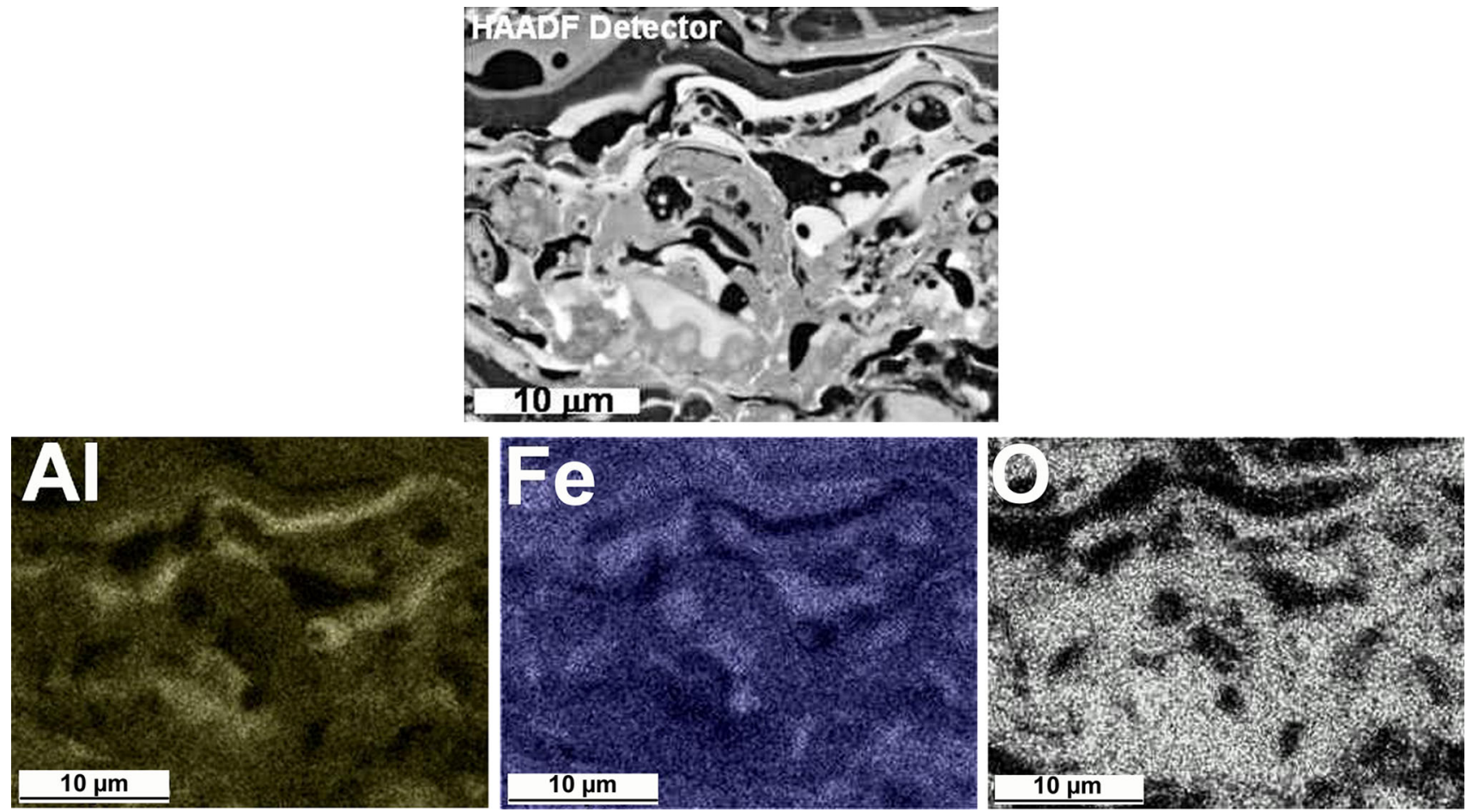

Fig. 11 STEM high-angle annular dark-field micrograph of GDS coating with corresponding EDX maps of Fe, Al, and O distributions

a wide range of compressive residual stresses is undoubtedly connected with the contribution of $\mathrm{B} 2$ and $\mathrm{D}_{3}$ antiphase domains in the nanocrystalline structure of the GDS coating.

It is obvious that the participation of the $\mathrm{Al}_{2} \mathrm{O}_{3}$ oxides affects the increase of the residual stress and strengthens the structure of the $\mathrm{FeAl}$ coating, the average hardness of which was estimated as approximately 1193 HV0.1 (Fig. 10). It must be emphasized that substantial microhardness fluctuations are observed, being due to a combination of the presence of hard oxide films (mainly $\mathrm{Al}_{2} \mathrm{O}_{3}$ ) in the deformed lamellar grains of the GDS coating, the varying aluminum content in the $\mathrm{FeAl}$ grains, and the oxidation of the $\mathrm{FeAl}$ phase.

Therefore, EDX mapping of the elemental distribution in the GDS coating was the next step to understand the nanocomposite-like phase structure of the $\mathrm{Fe}-\mathrm{Al}$ coating (Fig. 11). Since the layered structure of the coating consists of grains with varying degree of grayness as observed by a scanning TEM (STEM) detector, the qualitative analysis based on mappings helped to determine that $\mathrm{Fe}$ was present in very bright areas, being identified as $\mathrm{Fe}_{3} \mathrm{Al}$, and in less bright ones containing $\mathrm{FeAl}$ phase with $38-42$ at. \% Fe. Aluminum identified as $\mathrm{Al}_{2} \mathrm{O}_{3}$ was found in dark areas and grey grains, in which the occurrence of the $\mathrm{FeAl}$ phase with increased $\mathrm{Al}$ content was confirmed. Oxygen, similarly to aluminum, was found not only in the dark and dark-grey areas, but also in the direct vicinity of the $\mathrm{Fe}_{3} \mathrm{Al}$ phase, which formed sublayers with lamellar morphology.
The results obtained from the qualitative analysis of the alloying element distributions complemented by the electron diffraction analysis and EDX microanalysis led to the conclusions that the observed dark areas correspond to $\mathrm{Al}_{2} \mathrm{O}_{3}$ oxide, while the grey areas prevailing in the structure belong to the FeAl based solid solution with varying degree of oxidation. The bright and light-grey areas contain the defective $\mathrm{Fe}_{3} \mathrm{Al}$ phase. Finally, it should be noted that the coating sprayed by GDS using the as-milled self-decomposing powder revealed nanocomposite, ordered $\mathrm{B} 2 \mathrm{FeAl}$ and $\mathrm{D}_{3} \mathrm{Fe}_{3} \mathrm{Al}$ structure with aluminum oxide phases created in situ during the GDS process at interlamellar boundaries.

\section{Conclusions}

Based on the results of microstructural investigation of the feedstock powder material and as-sprayed $\mathrm{Fe}-\mathrm{Al}$ type intermetallic coatings, the following conclusions can be reached:

1. After $20 \mathrm{~h}$ of ball milling, the self-decomposing powder (which was subsequently successfully used in the GDS process) was composed of strongly oxidized and disordered $\mathrm{FeAl}$ secondary solution phase containing $8 \mathrm{~nm}$ crystallites and thin $\mathrm{Al}_{2} \mathrm{O}_{3}$ films covering the particle surfaces;

2. Complex oxide films, identified as $\mathrm{Al}_{2} \mathrm{O}_{3}$, which are created in the $\mathrm{FeAl}$ nanocrystalline structure, become 
a composite-like reinforcement in the intermetallic $\mathrm{Fe}-\mathrm{Al}$ powder particles, forming a nanocomposite-like coating material;

3. The constituent phases of the layer-like Fe-Al type coating (similarly to the self-decomposing powder particles) showed significant variation of $\mathrm{Al}$ content, indicating the occurrence of $\mathrm{FeAl}$ and $\mathrm{Fe}_{3} \mathrm{Al}$ phases, as well as a significant content of oxide phases, mainly $\mathrm{Al}_{2} \mathrm{O}_{3}$ and more complex phases of $\mathrm{Fe}+2 \mathrm{Al}_{2} \mathrm{O}_{4}$ type, which are added to the evidently composite-like morphology of the GDS coatings;

4. Due to the minimal thickness of the oxide films and layered morphology of the FeAl coating, the content of the oxides does not significantly influence the cohesive strength of the grain boundaries and is advantageous regarding the strengthening of the coating structure;

5. The average microhardness value of $1193 \mathrm{HV} 0.1$ is related to the content of ordered $\mathrm{B} 2 \mathrm{FeAl}$ and $\mathrm{DO}_{3}$ $\mathrm{Fe}_{3} \mathrm{Al}$ antiphase domains in the nanocrystalline structure of the GDS coating and above all to the hard oxide phases (mostly $\mathrm{Al}_{2} \mathrm{O}_{3}$ ) that considerably increase the average microhardness;

6. The content of oxides is responsible for the $\mathrm{Al}$ depletion of the FeAl phase and the formation of strongly defective $\mathrm{Fe}_{3} \mathrm{Al}$ phase with a significant density of dislocations in the vicinity of oxides;

7. Highly defective $\mathrm{FeAl}$ and $\mathrm{Fe}_{3} \mathrm{Al}$ phases, undergoing solid-state transformations (in the unmelted powder particles), were formed due to the strong effect of the impulse pressure which generated compressive residual stresses in the GDS coating. Such defectiveness provides evidence for plasticizing of the brittle $\mathrm{FeAl}$ phase during the detonation spraying process, additionally considering the fact that the embrittlement was intensified by the occurrence of $\mathrm{Al}_{2} \mathrm{O}_{3}$ ceramics, which made the FeAl coating composite like.

\section{Acknowledgements}

The author wishes to thank Dr. Dariusz Zasada from the Department of Advanced Materials and Technologies, Military University of Technology for his help in the experimental work. The author expresses his thanks to Prof. R.A. Varin from the University of Waterloo, Canada, for critical reading of the manuscript.

\section{Open Access}

This article is distributed under the terms of the Creative Commons Attribution License which permits any use, distribution, and reproduction in any medium, provided the original author(s) and the source are credited.

\section{References}

1. C.H. Xu, W. Gao, and Y.D. He, High Temperature Oxidation Behaviour of $\mathrm{FeAl}$ Intermetallics-Oxide Scales Formed in Ambient Atmosphere, Scr. Mater., 2000, 42, p 975-980

2. D.G. Morris, M.A. Muñoz-Morris, and J. Chao, Development of High Strength, High Ductility and High Creep Resistant Iron Aluminide, Intermetallics, 2004, 12, p 821-826

3. T. Durejko, S. Lipiński, Z. Bojar, and J. Bystrzycki, Processing and Characterization of Graded Metal/Intermetallic Materials: The Example of Fe/FeAl Intermetallics, Mater. Des., 2011, 32, p 2827-2834

4. M. Palm, Concepts Derived from Phase Diagram Studies for the Strengthening of Fe-Al-Based Alloys, Intermetallics, 2005, 13, p 1286-1295

5. M. Krasnowski, and T. Kulik, Nanocrystalline Al-Fe Intermetallics-Light Weight Alloys with High Hardness, Intermetallics, 2010, 18, p 47-50

6. J.M. Guilemany, N. Cinca, S. Dosta, and C.R.C. Lima, HighTemperature Oxidation of Fe40Al Coatings Obtained by HVOF Thermal Spray, Intermetallics, 2007, 15, p 1384-1394

7. M. Kupka, K. Stępień, and K. Kulak, Effect of Hydrogen on Room-Temperature Plasticity of B2 Iron Aluminides, Corros. Sci., 2011, 53, p 1209-1213

8. M. Guilemany, C.R.C. Lima, N. Cinca, and J.R. Miguel, Studies of Fe-40Al Coatings Obtained by High Velocity Oxy-Fuel, Surf. Coat. Technol., 2006, 201, p 2072-2079

9. Hong-Tao Wang, Chang-Jiu Li, Guan-Jun Yang, Cheng-Xin Li, Qiang Zhang, and Wen-Ya Li, Microstructural Characterization of Cold-Sprayed Nanostructured FeAl Intermetallic Compound Coating and Its Ball-Milled Feedstock Powders, J. Therm. Spray Technol., 2007, 16, p 669-676

10. Y. Guan-Jun, W. Hong-Tao, L. Chang-Jiu et al., Effect of Annealing on the Microstructure and Erosion Performance of Cold-Sprayed FeAl Intermetallic Coatings, Surf. Coat. Technol., 2011, 205(23-24), p 5502-5509

11. C. Xiao and W. Chen, Sulfidation Resistance of $\mathrm{CeO}_{2}$-Modified HVOF Sprayed FeAl Coatings at $700{ }^{\circ} \mathrm{C}$, Surf. Coat. Technol., 2001, 6, p 3625-3632

12. D.M. Yang and B.H. Tian, Microstructure and Mechanical Properties of FeAl Coating Deposited by Low Pressure Plasma, Appl. Mech. Mater., 2013, 333-335, p 1916-1920

13. T. Chmielewski, D.A. Golanski, New Method of In-Situ Fabrication of Protective Coatings Based on Fe-Al Intermetallic Compounds, Proc. Inst. Mech. Eng. B J. Eng. Manuf., 2011, 225(B4), p.611-616

14. G. Ji, O. Elkedim, and T. Grosdidier, Deposition and Corrosion Resistance of HVOF Sprayed Nanocrystalline Iron Aluminide Coatings, Surf. Coat. Technol., 2005, 190, p 406-416

15. Jingde Zhang, Yansheng Yin, Jing Li, and Hong Zhang, Fabrication and Properties of $\mathrm{Fe}_{3} \mathrm{Al}-\mathrm{Al}_{2} \mathrm{O}_{3}$ Graded Coatings, J. Mater. Process. Technol., 2003, 134(2), p 206-209

16. Zilin Yan, Qunying Huang, Zhihui Guo, Yong Song, Chunjing $\mathrm{Li}$, Shaojun Liu, Qian Han, and Changguang Deng, Vacuum Plasma Sprayed $\mathrm{FeAl} / \mathrm{Al}_{2} \mathrm{O}_{3}$ Functionally Graded Coatings for Fusion Reactor Applications, Fusion Eng. Des., 2010, 85(7-9), p $1542-1545$

17. N. Cinca and J.M. Guilemany, Thermal Spraying of Transition Metal Aluminides: an Overview, Intermetallics, 2012, 24, p 60-72

18. C. Senderowski and Z. Bojar, Influence of Detonation Gun Spraying Conditions on the Quality of Fe-Al Intermetallic Protective Coatings in the Presence of $\mathrm{NiAl}$ and $\mathrm{NiCr}$ Interlayers, J. Therm. Spray Technol., 2009, 18(3), p 435-447

19. C. Senderowski and Z. Bojar, Gas Detonation Spray Forming of Fe-Al Coatings in the Presence of Interlayer, Surf. Coat. Technol., 2008, 202, p 3538-3548

20. C. Senderowski, Z. Bojar, W. Wołczyński, and A. Pawłowski, Microstructure Characterization of D-Gun Sprayed Fe-Al Intermetallic Coatings, Intermetallics, 2010, 18, p 1405-1409 
21. C. Senderowski, Z. Bojar, W. Wołczyński, G. Roy, and T. Czujko, Residual Stresses Determined by the Modified Sachs Method Within a Gas Detonation Sprayed Coatings of the Fe-Al Intermetallic, Arch. Metall. Mater., 2007, 52(4), p 569-578

22. C. Senderowski, A. Pawłowski, Z. Bojar, W. Wołczyński, M. Faryna, J. Morgiel, and $€$. Major, TEM Microstructure of Fe-Al Coatings Detonation Sprayed onto Steel Substrate, Arch. Metall. Mater., 2010, 55(2), p 373-381

23. A. Pawłowski, T. Czeppe, Ł. Major, and C. Senderowski, Structure Morphology of Fe-Al Coating Detonation Sprayed onto Carbon Steel Substrate, Arch. Metall. Mater., 2009, 54(3), p 499-504

24. A. Pawłowski, C. Senderowski, Z. Bojar, and M. Faryna, Detonation Deposited $\mathrm{Fe}-\mathrm{Al}$ Coatings, Part I: The Interlayers $\mathrm{Ni}(\mathrm{Al})$ and $\mathrm{Ni}(\mathrm{Cr})$ and $\mathrm{Fe}-\mathrm{Al}$ Coating Detonation Sprayed onto Substrate of 045 Steel, Arch. Metall. Mater., 2010, 55(4), p 1061-1071

25. A. Pawłowski, C. Senderowski, W. Wołczyński, and J. Morgiel, Detonation Deposited Fe-Al Coatings, Part II: Transmission Electron Microscopy of Interlayers and $\mathrm{Fe}-\mathrm{Al}$ Intermetallic Coating Detonation Sprayed onto the 045 Steel Substrate, Arch. Metall. Mater., 2011, 56(1), p 71-79

26. A. Pawłowski, C. Senderowski, Z. Bojar, J. Bonarski, and $€$. Major, Detonation Deposited Fe-Al Coatings Part III: Morphology of the $\mathrm{Ni}(\mathrm{Cr})$ and $\mathrm{Ni}(\mathrm{Al})$ Interlayers and $\mathrm{Fe}-\mathrm{Al}$ Coating Sprayed onto the 045 Steel Substrate, Arch. Metall. Mater., 2011, 56(2), p 263-269

27. C. Senderowski, Z. Bojar, K. Łodziński, J. Morgiel, Principal mechanisms of the structure formation in Fe-Al type D-gun intermetallics coatings, Proceedings 20th International Federation for Heat Treatment and Surface Engineering Congress, Beijing (2012) p.746-751

28. W. Wołczyński, C. Senderowski, J. Morgiel, and G. Garzeł, D-Gun Sprayed Fe-Al Single Particle Solidification, Arch. Metall. Mater., 2014, 59(1), p 209-217

29. C. Senderowski, A. Panas, J. Paszula, Z. Bojar, The evaluation of $\mathrm{FeAl}$ particles thermal response in gas detonation thermal spraying process, Modern Technologies in Surface Engineering, V National Science Conference, 2013, Spala-Poland, Inżynieria Materiałowa, 2013, 6, p.849-853 (in Polish)

30. V. Ulianitsky, A. Shtertser, S. Zlobin, and I. Smurov, ComputerControlled Detonation Spraying: From Process Fundamentals Toward Advanced Applications, J. Therm. Spray Technol., 2011, 20(4), p 791-801

31. K. Ramadan and P. Barry Butler, Analysis of Particle Dynamics and Heat Transfer in Detonation Thermal Spraying Systems, J. Therm. Spray Technol., 2004, 13(2), p.248-264

32. D.V. Dudina, I.S. Batraev, V.Y. Ulianitsky, and M.A. Korchagin, Possibilities of the Computer-Controlled Detonation Spraying Method: A Chemistry Viewpoint, Ceram. Int., 2014, 40(2), p 3253-3260

33. C. Senderowski, K. Łodziński, Z. Bojar, Structure and Adhesion of D-Gun Sprayed and Heat Treated FeAl Coatings in the Presence of NiAl and Interlayer, Proceedings 20th International Federation for Heat Treatment and Surface Engineering Congress, Beijing (2012) p.740-745

34. P. Kratochvíl, The History of the Search and Use of Heat Resistant Pyroferal, Intermetallics, 2008, 16, p 587-591

35. A. Gierek, F. Binczyk, G. Pucka, K. Białożyt, T. Mikuszewski, The self-decomposition metallic powders-the technology of receiving, properties and application, Inżynieria Materiałowa, 1989, 2, p.51-54 (in Polish)

36. C. Senderowski, T. Durejko, Z. Bojar, The possible applications of self-decomposing intermetallic $\mathrm{Fe}-\mathrm{Al}$ type powders in the form of HVOF and D-gun spraying protective coatings, Powder Metallurgy World Congress \& Exhibition, 2010, Florence, p.43

37. R.A. Varin, J. Bystrzycki, and A. Calka, Characterization of Nanocrystalline Fe-45at\% Al Intermetallic Powders by Controlled Ball Milling and the Influence of Annealing, Intermetallics, 1999, 7, p 917-930 